\title{
Social withdrawal, observed peer acceptance, and the development of self-perceptions in children ages 4 to 7 years
}

\author{
Larry J. Nelson \\ Brigham Young University - Provo, larry_nelson@byu.edu \\ Kenneth H. Rubin \\ University of Maryland \\ Nathan A. Fox \\ University of Maryland
}

Follow this and additional works at: https://scholarsarchive.byu.edu/facpub

Part of the Other Social and Behavioral Sciences Commons

\section{Original Publication Citation}

Nelson, L. J., Rubin, K. H., \& Fox, N. A. (2005). Social withdrawal, observed peer acceptance, and the development of self-perceptions in children ages 4 to 7 years. Early Childhood Research Quarterly, 20, 185-200.

\section{BYU ScholarsArchive Citation}

Nelson, Larry J.; Rubin, Kenneth H.; and Fox, Nathan A., "Social withdrawal, observed peer acceptance, and the development of self-perceptions in children ages 4 to 7 years" (2005). Faculty Publications. 4673.

https://scholarsarchive.byu.edu/facpub/4673

This Peer-Reviewed Article is brought to you for free and open access by BYU ScholarsArchive. It has been accepted for inclusion in Faculty Publications by an authorized administrator of BYU ScholarsArchive. For more information, please contact ellen_amatangelo@byu.edu. 


\title{
Social withdrawal, observed peer acceptance, and the development of self-perceptions in children ages 4 to 7 years ${ }^{\text {is }}$
}

\author{
Larry J. Nelson $^{\mathrm{a}, *}$, Kenneth H. Rubin ${ }^{\mathrm{b}}$, Nathan A. Fox ${ }^{\mathrm{b}}$ \\ ${ }^{a}$ Marriage, Family, and Human Development, Brigham Young University, 2091 JFSB, Provo, UT 84602, USA \\ ${ }^{\mathrm{b}}$ University of Maryland, USA
}

\begin{abstract}
Children who think poorly about themselves are considered at-risk for a myriad of negative outcomes. Thus, it is important to explore possible origins of such cognitions, particularly in young children. The purpose of this study was to examine the relations between various nonsocial behaviors (i.e., reticence and social withdrawal), observed peer acceptance at ages 4 and 7 years, and self-perceptions at age 7 years in both boys and girls, respectively.

Participants included 163 children ( 89 females, 74 males) who were seen at age 4 and then again at age 7 years. For girls, results revealed that nonsocial behavior (both reticence and solitary-passive withdrawal) was negatively related to observed peer acceptance at both ages 4 and 7, and peer acceptance, as early as 4 years of age, was found to influence self-perceptions of competence at age 7 years. For boys, results revealed that (a) reticence at age 7 predicted negatively to perceived peer acceptance, perceived physical and perceived cognitive competence at age 7 years, (b) solitary-passive withdrawal at age 4 predicted positive cognitive self-perceptions at age 7 , and (c) solitary-passive withdrawal at age 7 predicted negatively to perceived peer acceptance and perceived physical competence at age 7 years.
\end{abstract}

(C) 2005 Elsevier Inc. All rights reserved.

Keywords: Self-perception; Social withdrawal; Children

\footnotetext{
th Portions of this paper were presented in the symposium R. Coplan \& C.H. Hart (Chairs), Multiple forms of shyness/withdrawal/inhibition: Conceptualizations, assessments, and outcomes at the Biennial Meeting of the Society for Research in Child Development, Minneapolis, Minnesota, April 2001.

* Corresponding author. Tel.: +1 801422 6711; fax: +1 8014220230.

E-mail address: larry_nelson@byu.edu (L.J. Nelson).
} 


\section{Introduction}

Children and adolescents who think poorly about themselves are considered at-risk for a myriad of negative outcomes, including depression (e.g., Harter \& Jackson, 1993), eating disorders (e.g., Heatherton \& Baumeister, 1991), and suicidal ideations (e.g., Harter, Marold, \& Whitesell, 1992). Conversely, positive self-perceptions have been found to be associated with favorable outcomes such as academic achievement (e.g., Marsh, 1990), and peer acceptance (e.g., Boivin \& Begin, 1989; Ladd \& Price, 1986). Given these outcomes, it would seem important to identify factors that begin to influence the development of selfconcepts, positively and negatively, early in a child's life.

\subsection{Individual differences in self-concepts}

Based on theories that underscore the importance of interaction with others in the development of the self (e.g., Cooley, 1902; Mead, 1925, 1934), it might be assumed that individual differences in self-concepts may emerge based on the amount and types of interactions children have with peers. In particular, there is evidence that children who interact with, and are accepted by peers, tend to have positive self-perceptions while socially withdrawn and rejected children tend to have more negative selfperceptions. For example, socially fearful and withdrawn behaviors have been found to be associated with low self-perceptions in middle-childhood (Boivin \& Hymel, 1997; Hymel, Bowker, \& Woody, 1993; Hymel, Woody, \& Bowker, 1993; Rubin \& Mills, 1988), late childhood/early adolescence (Hymel, Rubin, Rowden, \& LeMare, 1990; Rubin, Chen, \& Hymel, 1993), and adolescence (Rubin, 1993a, 1993b; Rubin, Chen, McDougall, Bowker, \& McKinnon, 1995). However, few if any researchers have examined the longitudinal relations between self-perceptions and specific subtypes of nonsocial behaviors in early childhood. Furthermore, few if any researchers have examined the relations between social withdrawal and self-perceptions over time. Therefore, there is a need to conduct longitudinal examinations of the relations between withdrawal and the development of self-perceptions in early childhood because it is critical to understand how early experiences influence subsequent development.

Additionally, few if any researchers have investigated the role that peer acceptance or rejection might play in the development of self-perceptions across early childhood. Given that social withdrawal is related to both peer rejection and negative self-perceptions, there has been debate as to whether or not withdrawal and rejection both make independent contributions in predicting negative outcomes. One of the first studies to separate the effects of withdrawal and peer acceptance/rejection on self-perceptions was conducted by Boivin and Hymel (1997); they found that for children between the ages of 8 and 10, peer status partially mediated the impact of withdrawal on perceived peer acceptance but that both made unique contributions to perceived acceptance (i.e., withdrawal was negatively associated with perceived social acceptance whilst peer acceptance was positively associated with perceived social acceptance).

Based on these findings, it would seem important to examine the effects of both nonsocial behaviors and peer acceptance on developing self-perceptions. Furthermore, because Boivin and Hymel (1997) used a global index of withdrawal and examined data collected at only one point in time, it would also seem important to examine the effects of various nonsocial behaviors and peer rejection over time, beginning in the early stages of the development of self-perceptions, in order to identify factors that may place children at-risk of developing negative self-perceptions. Finally, in regard to the relation between peer acceptance and self-perceptions, there is a need to examine more direct experiences with acceptance and rejection by peers because most researchers who have examined peer acceptance have only used peer 
nomination or peer rating methods of assessment. For example, in examining the relation between social self-concept and 'actual' peer acceptance, Berndt and Burgy (1996) reviewed 11 studies conducted on the topic. All of the studies used teacher or peer ratings/nominations as measures of acceptance. Boivin and Hymel (1997) pointed out that these types of indices "only reflect the affective evaluations of the group, attitudes to which the child does not necessarily have direct access (p. 136)." Boivin and Hymel then asked, "How, then, do peer attitudes influence children's social self-perceptions (p. 136)?" One possible answer is that children's self-perceptions are influenced by their direct experiences of acceptance and rejection during peer interactions. Thus, it would appear important to examine children actually being accepted, rejected, or neglected. This is particularly important given that observations of children have revealed that withdrawn children's attempts at social initiations are less successful than those of their more sociable peers (e.g., Stewart \& Rubin, 1995); such experiences may reinforce or lead to negative thoughts about one's relationships and social skills. Thus, it is necessary to study how these actual experiences with peers, rather than peer rating scores, may play a role in the development if self-perceptions.

To address these issues, this study attempted to examine the relations between various nonsocial behaviors (i.e., reticence and solitary-passive withdrawal) and observed peer acceptance at ages 4 and 7 years and self-perceptions at age 7 years. It was expected that both withdrawal and acceptance (or the lack thereof) would make unique contributions to children's self-perceptions. Specifically, based on theories (e.g., Cooley, 1902; Mead, 1925) that underscore the importance of interaction with others in the development of the self, it was expected that withdrawal would influence self-perceptions negatively while peer acceptance would be positively associated with developing self-perceptions. However, it was expected that varying forms of withdrawal would have different relations with developing self-perceptions. Specific hypotheses related to respective forms of withdrawal and specific domains of the self will follow a discussion of the various nonsocial behaviors that have been identified in early childhood.

\subsection{Nonsocial behaviors and self-perceptions}

In an effort to better understand nonsocial behaviors in children, a number of empirical studies have delineated multiple forms of behavioral solitude (see Rubin, Burgess, Kennedy, \& Stewart, 2003, for a recent review). For example, two types of nonsocial behaviors that are observed during the preschool years are solitary-passive withdrawal and reticence. Solitary-passive withdrawal comprises the quiescent exploration of objects and/or constructive activity while playing alone (Coplan, Rubin, Fox, Calkins, \& Stewart, 1994; Rubin, 1982). Examples of this type of activity include engaging in artwork, puzzles, or block construction by oneself; building or fixing something alone; or exploring something alone.

In early childhood, solitary-passive withdrawal is associated positively with (a) competent problem solving while alone or in cooperative tasks with peers, (b) task persistence, (c) performance on objectoriented tasks, and (c) indices of emotion regulation (Coplan et al., 1994; Coplan \& Rubin, 1998; Rubin, Chen, et al., 1995; Rubin, Coplan, Fox, \& Calkins, 1995). However, children who frequently engage in solitary-passive withdrawal perform poorly during people-oriented social tasks (e.g., "show and tell", during small group time; Coplan \& Rubin, 1998; Coplan et al., 1994) which may suggest that there are some children who engage in solitary-passive behaviors who experience difficulties in social settings. As will be noted below, such difficulties may be more pronounced for boys than girls.

A second type of observed nonsocial behavior is reticence. This behavior consists of onlooking (prolonged looking at peers without accompanying play) or being unoccupied (doing nothing; Coplan et al., 1994). Reticence is believed to reflect social fear and anxiety in a social context. Preschool-age children 
who frequently engage in reticent behavior are believed to be trapped in a social "approach-avoidance" conflict (Asendorpf, 1990, 1991). That is, while they want to approach others, they have a simultaneous avoidance tendency. Reticence is associated with overt indices of anxiety (e.g., crying, and automanipulatives such as digit sucking and hair pulling; Coplan et al., 1994; Coplan \& Rubin, 1998), teacher ratings of social maladjustment (Rubin, 1982), peer rejection (Hart et al., 2000), and the inability to regulate negative emotions (Rubin, Coplan, et al., 1995).

Based on this evidence, there appears to be important differences in the correlates of solitary-passive withdrawal and reticence. Thus, in studying the relation between withdrawal and the development of the self, it is important to examine specific types of solitude rather than focusing on global indices of withdrawal. It is also important to examine these relations longitudinally to explore for developmental differences in the associations between forms of withdrawal and self-perceptions.

\subsection{Gender differences}

Gender may also play an important role in the relations between nonsocial behaviors, peer acceptance, and self-perceptions. There is evidence to suggest that withdrawal may be (a) less acceptable for boys than girls, (b) somewhat encouraged in girls, and (c) related to adjustment problems in boys but not girls (e.g., Engfer, 1993; Radke-Yarrow, Richters, \& Wilson, 1988; Rubin et al., 1993; Stevenson-Hinde, 1989). Given these findings, one might think that boys and girls would differ in the frequency of their display of withdrawn behaviors but researchers have not typically found significant gender differences in the display of various nonsocial behaviors (Coplan, Molina, Lagace-Seguin, \& Wichmann, 2001; Coplan et al., 1994; Coplan \& Rubin, 1998; Rubin, 1982). They have, however, found gender differences in the correlates of these behaviors. Specifically, nonsocial boys tend to have more adjustment difficulties than girls. Among preschoolers, for example, shy boys have more behavior problems than shy girls (Simpson \& Stevenson-Hinde, 1985). In kindergarten, solitary-passive withdrawal in boys has been found to be negatively associated with social competence and positively associated with shyness and internalizing disorders, while the reverse has been found for girls (Coplan et al., 2001). In middle childhood, sociallywithdrawn boys, but not girls, report being more lonely and having poorer social skills than their average peers (Rubin et al., 1993). In adolescence, shy boys tend to have lower self-esteem than shy girls (Morison \& Masten, 1991). Finally, Caspi, Elder, and Bem (1988) found that males who were shy in childhood were more likely to marry, become fathers, and establish careers at a later age than their non-shy peers, while females who were shy in childhood did not marry or start families later than other women within the same cohort. Taken together, this evidence suggests that being nonsocial has greater psychological costs for males than females. However, how these gender differences in various forms of withdrawal are related to self-perceptions in boys and girls, respectively, is yet to be explored in early childhood.

There may be other gender differences, as well, which play important roles in the relations between nonsocial behaviors, peer acceptance, and self-perceptions. It is possible that a lack of peer acceptance may have more negative effects on the developing self-concepts of young girls than boys, particularly insofar as self-perceptions of relationships are concerned. Conceptually, the assumption that failure in the peer group would have more negative implications for young girls than boys was derived from gender socialization literature that females are particularly attuned to relationships and the ethics of caring (Chodorow, 1989; Gilligan, 1982; Huston, 1983; Miller, 1986). In support of this notion, Harter and Jackson (1993) found that adolescent girls were significantly more likely to find fault with their social behavior (how they treat significant others with whom they have a relationship) than are boys. Similarly, 
adolescent girls were less likely to find fault with themselves in domains of competence than they were with regard to social relationships (Harter \& Jackson, 1993).

Taken together, there is evidence that nonsocial behavior in boys, and peer rejection for girls, may have negative implications on the development of self-perceptions. Therefore, it was expected that reticence, at both age 4 and 7 years, would be negatively related to self-perceptions of peer acceptance and physical and cognitive competence for boys. In contrast to reticent behavior, it was expected that the relation between solitary-passive withdrawal and self-perceptions would change over time. Specifically, it was hypothesized that, because preschoolers who engage in solitary-passive behaviors tend to perform well in cognitive tasks (e.g., Rubin, 1982), solitary-passive withdrawal at age 4 would predict positive selfperceptions of cognitive competence at age 7 years. Also, because preschoolers who engage in solitarypassive withdrawal can interact socially when necessary (e.g., Coplan et al., 1994; Rubin, 1982), they most likely do not perceive anything wrong with their peer relationships. However, as children get older, there is ample evidence that withdrawal of any kind becomes increasingly salient to, and considered maladaptive, by the peer group (e.g., Younger, Gentile, \& Burgess, 1993). Furthermore, there is evidence that solitary-passive withdrawal becomes increasingly related to maladjustment, including negative selfperceptions at age 7 (e.g., Asendorpf, 1993). Therefore, it was expected that solitary-passive withdrawal at age 7 years, particularly for boys, would be negatively associated with self-perceptions at the same age. With regard to peer acceptance, it was predicted that peer acceptance at both time periods would be positively related to self-perceptions at age 7 years. Based on the notion that girls are more concerned with relationships than boys (Chodorow, 1989; Gilligan, 1982; Huston, 1983; Miller, 1986), it was predicted that the association between peer acceptance and the emergence of positive self-perceptions would be particularly strong for girls.

\section{Methods}

\subsection{Participants}

Parental consent for child participation was obtained for 243 preschool age children who lived in or around Washington, DC and its suburbs in Virginia and Maryland. After participating at age 4, the children were asked to participate again at age 7 years. Of those 243 preschool-age children, a total of 163 (89 females, 74 males) of these children participated and had complete data sets at both time points. (Although the attrition rate was approximately $33 \%$, there were no significant differences between those children who dropped out of the study and those who remained on any of the variables assessed at age 4.) Children were approximately $41 / 2$ years of age at their first visit $(M=4.63$ years, S.D. $=0.37$ for all participants; $M=4.62$ years, S.D. $=0.39$ for boys; $M=4.65$ years, S.D. $=0.35$ for girls), and approximately 7 years of age at the second visit $(M=7.34$ years, S.D. $=0.32$ for all participants; $M=7.37$ years, S.D. $=0.35$ for boys; $M=7.34$ years, S.D. $=0.28$ for girls). The participants were predominately Caucasian and middle class.

\subsection{Procedures and measures}

\subsubsection{Behavioral observations}

The procedure used in this study has been reported and used in other studies (e.g., Rubin, Chen, et al., 1995; Rubin, Coplan, et al., 1995). At both ages 4 and 7 years, participants were invited to a university 
laboratory where they were assigned to quartets ${ }^{1}$ of unfamiliar same-sex and same-age peers who were also participants in the study. Children were introduced into a small playroom filled with age-appropriate toys. Each visit consisted of five episodes including two 15-minute sessions of unstructured free play. During these episodes, including the two free play sessions, children were observed and their behaviors videotaped through a one-way mirror.

In this study, each child's behaviors in the first of the two sessions were coded using Rubin's (2001) Play Observation Scale (POS). Ten-second intervals were coded for social participation (unoccupied, onlooking, solitary play, parallel play, conversation, group play) and the cognitive quality of play (functional, dramatic, and constructive play; exploration; games with rules). Approximately 90 intervals were coded per child in each of the free-play sessions $(M=88.87$, S.D. $=12.05$ for boys, $M=89.13$, S.D. $=8.12$ for girls).

Reticent behavior was computed by summing the proportion of 10 -second intervals engaged in unoccupied or onlooking behaviors. Solitary-passive withdrawal was computed by summing the proportion of 10-second intervals spent in solitary-exploratory or solitary-constructive play.

Behaviors were coded by 10 independent observers (five at each time point). Interrater reliability was assessed using a randomly selected group of children, totaling approximately $30 \%$ of the sample. For a complete variable matrix, including social and cognitive play categories, Cohen's Kappa between observer pairs ranged from $K=0.84$ to $K=0.88$. Intercoder disagreements were resolved by review and discussion.

\subsubsection{Peer acceptance}

For the current study, peer acceptance was defined as the successful outcome of a peer-directed initiation. At both ages, children's assertive social initiations were coded from the video tapes using a modification of a taxonomic scheme (Stoneman, Brody, \& McKinnon, 1984) which has been reported and used in other studies (e.g., Rubin, 1985). At both ages, this procedure was used to assess peer acceptance (i.e., successful social initiations) in the second free-play session of the laboratory visit described above. An initiation sequence was coded if the focal child initiated an interaction with another child. Attempts at interactions could include (1) a managerial initiation (verbal or nonverbal request for a particular behavior, or ceasing of a particular behavior, from the partner); (2) a teaching initiation (explaining or demonstrating things to another child); or (3) a learning initiation (verbal or nonverbal request for an explanation). As per Rubin (1985), the initiation attempt was coded as a success if the recipient complied with the target child's request within 10 seconds. In an attempt to measure the role of positive feedback (i.e., acceptance) on self-perceptions, the total number of successful initiations was used as an observed index of peer acceptance.

These initiations were coded by eight observers (four at each time point). Interrater reliability was assessed using a randomly selected group of children, totaling approximately $30 \%$ of the sample. For the categories of assertive initiations and the responses to them, Cohen's Kappa between observer pairs ranged from $K=0.81$ to $K=0.85$. Intercoder disagreements were resolved by review and discussion.

\footnotetext{
1 The odd number of participants (169) in the study might raise concern as to whether or not all children participated in quartets. All participants in this study did indeed participate in full quartets because there were children who participated in the quartets but who were then excluded from this study due to incomplete data sets at one of the time points.
} 


\subsubsection{Perceived competence and acceptance}

Children's perceived competence was assessed at age 7 years using the Pictorial Scale of Perceived Competence and Social Acceptance for Young Children (Harter \& Pike, 1984). This 24-item instrument contains four subscales designed to assess young children's perceptions of their physical competence and cognitive competence as well as their perceptions of their relationships with their peers and mothers. Each item was rated on a four-point scale, where 4 was most competent and 1 was least competent. Items were averaged within each subscale to provide a single mean score in each domain including physical competence ( $\alpha=0.73$ for boys, $\alpha=0.73$ for girls), cognitive competence ( $\alpha=0.73$ for boys, $\alpha=0.68$ for girls), and peer acceptance ( $\alpha=0.82$ for boys, $\alpha=0.71$ for girls). Given the study's focus on perceived competence and peer relationships, maternal acceptance was not included in the analyses.

\section{Results}

\subsection{Preliminary analyses}

Given the theoretically proposed differences between boys and girls in the meanings of the variables included in this study, it was important to examine gender differences. Therefore, all analyses were conducted separately by gender (except when comparisons were made between boys and girls). The variables examined in the study included observed solitary-passive and reticent behaviors at ages 4 and 7 years, observed peer acceptance at ages 4 and 7 years, and self-perceptions in three areas (i.e., perceived physical and cognitive competence, and perceived peer acceptance) at age 7 years.

Means and standard deviations for all variables are presented in Table 1. Gender differences in the frequency of the various behaviors and observed peer acceptance, as well as scores of self-perceptions, were assessed. Results from a series of $t$-tests indicated no statistically significant differences between boys and girls on any of the variables except for two; boys engaged in significantly more reticent behavior, $t(161)=2.30, p<0.05, d=0.36$, and solitary-passive withdrawal, $t(161)=2.03, p<0.05, d=0.32$, than girls at age 7 .

Table 1

Means, standard, deviations, and ranges of all variables ( $N=163 ; 89$ females, 74 males $)$

\begin{tabular}{|c|c|c|c|c|c|c|c|c|}
\hline \multirow[t]{2}{*}{ Variable } & \multicolumn{2}{|l|}{ Mean } & \multicolumn{2}{|c|}{ Standard deviation } & \multicolumn{2}{|c|}{ Minimum } & \multicolumn{2}{|c|}{ Maximum } \\
\hline & Boys & Girls & Boys & Girls & Boys & Girls & Boys & Girls \\
\hline \multicolumn{9}{|l|}{ Age 4} \\
\hline Reticence & 0.19 & 0.17 & 0.21 & 0.15 & 0.02 & 0.00 & 1.00 & 0.86 \\
\hline Solitary-passive withdrawal & 0.26 & 0.29 & 0.19 & 0.23 & 0.00 & 0.00 & 0.71 & 0.87 \\
\hline Observed peer acceptance & 3.92 & 5.35 & 4.23 & 5.84 & 0.00 & 0.00 & 15.00 & 29.00 \\
\hline \multicolumn{9}{|l|}{ Age 7} \\
\hline Reticence & 0.16 & 0.11 & 0.16 & 0.09 & 0.00 & 0.00 & 1.00 & 0.52 \\
\hline Solitary-passive withdrawal & 0.15 & 0.11 & 0.13 & 0.13 & 0.00 & 0.00 & 0.60 & 0.65 \\
\hline Observed peer acceptance & 6.46 & 6.48 & 4.63 & 4.60 & 0.00 & 0.00 & 20.00 & 26.00 \\
\hline Perceived peer acceptance & 3.03 & 3.00 & 0.60 & 0.54 & 1.50 & 2.00 & 4.00 & 4.00 \\
\hline Perceived physical competence & 3.39 & 3.51 & 0.49 & 0.42 & 2.17 & 2.33 & 4.00 & 4.00 \\
\hline Perceived cognitive competence & 3.51 & 3.53 & 0.44 & 0.40 & 2.50 & 2.17 & 4.00 & 4.00 \\
\hline
\end{tabular}


Table 2

Correlations of all variables $(N=163 ; 89$ females, 74 males $)$

\begin{tabular}{lllllllllll}
\hline Variable & 1 & 2 & 3 & 4 & 5 & 6 & 7 & 8 & 9 & 10 \\
\hline
\end{tabular}

Age 4

(1) Reticence

$\begin{array}{ll}\text { Boys } & 1.00 \\ \text { Girls } & 1.00\end{array}$

(2) Solitary-passive withdrawal

$\begin{array}{lll}\text { Boys } & -0.34^{* *} & 1.00 \\ \text { Girls } & -0.01 & 1.00\end{array}$

(3) Observed peer acceptance

$\begin{array}{llll}\text { Boys } & -0.27^{*} & -0.26^{*} & 1.00 \\ \text { Girls } & -0.21^{\wedge} & -0.29^{* *} & 1.00\end{array}$

Age 7

(4) Reticence

\begin{tabular}{|c|c|c|c|}
\hline Boys & $0.41^{* *}$ & $-0.24^{*}$ & -0.07 \\
\hline Girls & 0.11 & 0.04 & -0.08 \\
\hline
\end{tabular}

(5) Solitary-passive withdrawal

$\begin{array}{llllll}\text { Boys } & -0.08 & -0.05 & 0.06 & -0.16 & 1.00 \\ \text { Girls } & -0.03 & 0.10 & 0.03 & 0.11 & 1.00\end{array}$

(6) Observed peer acceptance
Boys $\quad-0.17 \quad-0.05$
Girls $\quad-0.16 \quad-0.10$
$\begin{array}{llll}0.05 & -0.41^{* *} & -0.03 & 1.00\end{array}$
$\begin{array}{llll}0.21^{*} & -0.27^{*} & -0.10 & 1.00\end{array}$

(7) Perceived peer acceptance

$\begin{array}{llllllll}\text { Boys } & -0.18 & 0.06 & 0.13 & -0.30^{* *} & -0.18 & 0.21^{\wedge} & 1.00 \\ \text { Girls } & -0.07 & -0.15 & 0.10 & 0.07 & 0.01 & -0.02 & 1.00\end{array}$

(8) Perceived physical competence

$\begin{array}{lllllllll}\text { Boys } & -0.33^{* *} & 0.06 & 0.09 & -0.33^{* *} & -0.14 & 0.10 & 0.62^{* *} & 1.00 \\ \text { Girls } & -0.05 & -0.06 & 0.22 & 0.05 & 0.09 & -0.06 & 0.30^{* *} & 1.00\end{array}$

(9) Perceived cognitive competence

$\begin{array}{llllllllll}\text { Boys } & -0.21^{\wedge} & 0.39^{* *} & -0.05 & -0.41^{* *} & 0.04 & 0.14 & 0.27^{*} & 0.24^{*} & 1.00 \\ \text { Girls } & 0.02 & 0.08 & 0.18^{\wedge} & 0.05 & 0.05 & 0.04 & 0.36^{* *} & 0.27^{*} & 1.00\end{array}$

${ }^{*} p<0.05$.

** $p<0.01$.

$\hat{p}<0.10$.

Correlations, by gender, between all of the variables are presented in Table 2. Both reticence, $r(163)=-0.27, p<0.05$, and solitary-passive withdrawal, $r(163)=-0.26, p<0.05$, were negatively related to observed peer acceptance at age four for boys. For girls, reticence was negatively correlated with observed peer acceptance, $r(163)=-0.29, p<0.01$, at age four; the negative correlation between solitarypassive withdrawal and observed peer acceptance approached significance, $r(163)=-0.21, p<0.06$. At age 7 , there was a negative correlation between reticence and observed peer acceptance for both boys, $r(163)=-0.41, p<0.01$, and girls, $r(163)=-0.27, p<0.05$.

Within-sex age differences in the frequency of the various behaviors and observed peer acceptance were assessed for boys and girls, respectively. For boys, results of a series of paired-sample $t$-tests indicated 
Table 3

Regression analyses examining the influence of reticence, solitary-passive withdrawal, and peer acceptance at ages 4 and 7 on self-perceptions at age 7 ( $N=163$; 89 females, 74 males for all analyses)

\begin{tabular}{|c|c|c|c|c|c|c|c|c|c|c|c|c|c|c|c|c|c|c|}
\hline & \multicolumn{6}{|c|}{ Perceived cognitive competence } & \multicolumn{6}{|c|}{ Perceived physical competence } & \multicolumn{6}{|c|}{ Perceived peer acceptance } \\
\hline & \multicolumn{3}{|l|}{ Males } & \multicolumn{3}{|c|}{ Females } & \multicolumn{3}{|l|}{ Males } & \multicolumn{3}{|l|}{ Females } & \multicolumn{3}{|l|}{ Males } & \multicolumn{3}{|c|}{ Females } \\
\hline & $B$ & S.E. $B$ & $\beta$ & $B$ & S.E. $B$ & $\beta$ & $B$ & S.E. $B$ & $\beta$ & $B$ & S.E. $B$ & $\beta$ & $B$ & S.E. $B$ & $\beta$ & $B$ & S.E. $B$ & $\beta$ \\
\hline \multicolumn{19}{|l|}{ Variables at age 4} \\
\hline Reticence & 0.11 & 0.28 & 0.05 & 0.21 & 0.30 & 0.08 & -0.66 & 0.32 & $-0.28^{*}$ & -0.04 & 0.31 & -0.02 & -0.10 & 0.40 & -0.03 & -0.27 & 0.41 & -0.07 \\
\hline $\begin{array}{c}\text { Solitary-passive } \\
\text { withdrawal }\end{array}$ & 0.79 & 0.30 & $0.33^{*}$ & 0.25 & 0.20 & 0.15 & -0.34 & 0.34 & -0.13 & -0.01 & 0.20 & -0.01 & -0.01 & 0.43 & 0.00 & -0.34 & 0.27 & -0.15 \\
\hline Peer acceptance & 0.00 & 0.01 & 0.02 & 0.02 & 0.01 & $0.23^{\wedge}$ & 0.00 & 0.01 & -0.02 & 0.02 & 0.01 & $0.24^{*}$ & 0.02 & 0.02 & 0.11 & 0.01 & 0.01 & 0.06 \\
\hline \multicolumn{19}{|l|}{ Variables at age 7} \\
\hline Reticence & -0.95 & 0.36 & $-0.34^{*}$ & -0.19 & 0.48 & -0.05 & -0.96 & 0.41 & $-0.31^{*}$ & 0.18 & 0.50 & 0.04 & -1.10 & 0.52 & $-0.29^{*}$ & 0.44 & 0.65 & 0.08 \\
\hline $\begin{array}{c}\text { Solitary-passive } \\
\text { withdrawal }\end{array}$ & 0.03 & 0.38 & 0.01 & 0.11 & 0.33 & 0.04 & -0.87 & 0.44 & $-0.22^{*}$ & 0.21 & 0.34 & 0.07 & -1.15 & 0.55 & $-0.24^{*}$ & 0.03 & 0.44 & 0.01 \\
\hline Peer acceptance & 0.00 & 0.01 & 0.02 & 0.00 & 0.01 & 0.01 & -0.01 & 0.01 & -0.08 & -0.010 & 0.01 & -0.10 & 0.01 & 0.02 & 0.08 & 0.00 & 0.01 & -0.03 \\
\hline
\end{tabular}


statistically significant differences between ages 4 and 7 in the following variables. Boys engaged in significantly more solitary-passive withdrawal at age 4 that at age $7, t(73)=4.14, p<0.01, d=0.70$, and, likewise, experienced lower observed peer acceptance at age 4 than at age $7, t(73)=3.58, p<0.01, d=0.57$. No differences were found for reticence.

For girls, results of a series of paired-sample $t$-tests indicated statistically significant differences between ages 4 and 7 for the following variables. Girls engaged in significantly more reticence, $t(88)=3.08$, $p<0.01, d=0.44$, and solitary-passive withdrawal, $t(88)=6.70, p<0.01, d=0.60$, at age 4 than at age 7 . No differences were found for observed peer acceptance.

\subsection{Regression analyses}

To examine the influence that nonsocial behaviors (solitary-passive withdrawal and reticence) and peer acceptance have on self-perceptions, a series of regression analyses were computed. Given the small sample size relative to the number of variables, interaction terms including gender could not be included in analyses. However, based on the results of the correlational analyses, it appears the relations between nonsocial behaviors and self-perceptions differ according to gender. Therefore, all of the regression analyses were conducted separately for boys and girls with all of the independent variables entered as a block in each of the three analyses.

In the first analyses, the dependent variable was age 7 perceived cognitive competence. The independent variables were age 4 reticence and solitary-passive withdrawal, age 4 peer acceptance, age 7 reticence and solitary-passive withdrawal, and age 7 peer acceptance. For boys, results (see Table 3 ) indicated that age 4 solitary-passive withdrawal positively predicted age 7 perceived cognitive competence $(\beta=0.33, p<0.05)$, while reticence at age 7 negatively predicted perceived cognitive competence $(\beta=-0.24, p<0.05)$. For girls (see Table 3$)$ age 4 peer acceptance tended to predict perceived cognitive competence $(\beta=0.23$, $p<0.06)$.

In the second analyses, the dependent variable was age 7 perceived physical competence. The independent variables were age 4 reticence and solitary-passive withdrawal, age 4 peer acceptance, age 7 reticence and solitary-passive withdrawal, and age 7 peer acceptance. For boys, results (see Table 3 ) indicated that age 4 reticence $(\beta=-0.28, p<0.05)$, age 7 reticence $(\beta=-0.31, p<0.05)$, and age 7 solitary-passive withdrawal $(\beta=-0.22, p<0.05)$ all negatively predicted age 7 perceived physical competence. For girls, results (see Table 3 ) revealed a positive relation between age 4 peer acceptance and perceived physical competence $(\beta=0.24, p<0.05)$.

In the final analyses, the dependent variable was age 7 perceived peer acceptance. The independent variables were age 4 reticence and solitary-passive withdrawal, age 4 peer acceptance, age 7 reticence and solitary-passive withdrawal, and age 7 peer acceptance. For boys, results (see Table 3 ) indicated that age 7 reticence $(\beta=-0.29, p<0.05)$, and age 7 solitary-passive withdrawal $(\beta=-0.24, p<0.05)$ both negatively predicted age 7 perceived peer acceptance. No significant associations were found for girls (see Table 3).

\section{Discussion}

The purpose of this study was to examine the relations between various nonsocial behaviors (i.e., reticence and social withdrawal), observed peer acceptance, and self-perceptions in boys and girls, re- 
spectively. Findings suggest that the display of various nonsocial behaviors as early as age 4 can influence the development of self-perceptions, particularly for boys. Specifically, results revealed that (a) reticence at age 7 predicted negatively to perceived peer acceptance, perceived physical and perceived cognitive competence at age 7 years, (b) solitary-passive withdrawal at age 4 predicted positive cognitive selfperceptions at age 7, and (c) solitary-passive withdrawal at age 7 predicted negatively to perceived peer acceptance and perceived physical competence at age 7 years. For girls, two distinct findings were revealed. First, results showed that nonsocial behavior (both reticence and solitary-passive withdrawal) was negatively related to observed peer acceptance at both ages 4 and 7. Second, peer acceptance, as early as 4 years of age, was found to influence self-perceptions of competence at age 7 years.

In general, the hypotheses for girls were confirmed in that peer acceptance appears to play a greater role in the development of self-perceptions of competence than does nonsocial behavior. Specifically, while correlations at both ages 4 and 7 revealed a negative correlation between both nonsocial behaviors and peer acceptance, it was observed peer acceptance at age 4 rather than nonsocial behaviors, that was found to predict self-perceptions of competence at age 7. In general, it appears that nonsocial behaviors may not play as significant a role in the development of self-perceptions for girls, adding to the growing body of literature which suggests that nonsocial behaviors are not related to adjustment problems in girls (e.g., Coplan et al., 2001; Morison \& Masten, 1991; Rubin et al., 1993).

The hypotheses concerning boys were also supported. The results suggest that most nonsocial behaviors play a significantly negative role in the development of boys' self-perceptions. These findings contribute to the growing body of literature which suggests that nonsocial behaviors, in general, are related to adjustment problems in boys (e.g., Coplan et al., 2001; Morison \& Masten, 1991; Rubin et al., 1993). However, the findings also demonstrated that the relation between withdrawal and self-perceptions depended heavily on the type of withdrawal displayed and the age in which it is displayed. Specific findings for various forms of withdrawal and their implications for understanding their roles in the development of self-perceptions will be discussed.

\subsection{Solitary-passive withdrawal}

Solitary-passive withdrawal has long been considered a 'benign' (e.g., Rubin, 1982) form of nonsocial play in early childhood due to the lack of significant relations between solitary-passive withdrawal and indices of maladjustment during this time period (Coplan et al., 1994; Coplan \& Rubin, 1998; Hart et al., 2000; Rubin, 1982). Until recently, however, few if any researchers have examined the role of gender in these relations. In a study aimed at exploring gender differences in nonsocial play and adjustment in kindergarten-age children, Coplan et al. (2001) discovered that solitary-passive withdrawal may only be benign for girls. Coplan and colleagues did not find solitary-passive withdrawal displayed by kindergartenage girls to be related to any indices of maladjustment, while actually finding it to be positively correlated with several indices of adjustment (i.e., fewer internalizing problems, higher social competence, and higher levels of academic achievement). For boys, however, Coplan and colleagues found that the frequent display of solitary-passive withdrawal was positively associated with a variety of adjustment difficulties (e.g., internalizing problems), and negatively associated with outcomes such as social competence.

Findings from the present study support the notion that solitary-passive withdrawal displayed by girls in early childhood may be a benign form of nonsocial behavior. Specifically, no relations between solitarypassive withdrawal and self-perceptions were found. This is particularly meaningful because it is the first longitudinal study to suggest that self-perceptions are another specific aspect of adjustment for girls in 
early childhood that do not appear to be affected by solitary-passive withdrawal directly. However, as will be discussed below, it may still pose an indirect threat to self-perceptions.

For boys in the current study, results revealed both positive and negative outcomes associated with this form of solitary play. First, as hypothesized, solitary-passive withdrawal at age 4 was a positive predictor of perceived cognitive competence. It appears that as boys engage in the cognitively stimulating behaviors of constructive and exploratory play, they begin to gain confidence in their cognitive abilities. This finding is significant in that this is one of the first studies to demonstrate, longitudinally, that a specific form of nonsocial behavior as early as age 4 can positively predict subsequent self-perceptions. However, while perceptions of one's cognitive abilities may be fostered by solitary-passive behaviors, peer relationships may be harmed by these behaviors as early as age 4 . At this age, the display of solitary-passive withdrawal was negatively related to observed peer acceptance. This is consistent with findings from other researchers who have found that children who frequently engage in solitary-passive withdrawal perform poorly during social tasks (Coplan et al., 1994; Coplan \& Rubin, 1998) and demonstrate greater shyness and less social competence than their peers (Coplan et al., 2001). Hence, boys who frequently engage in solitary-passive behavior may be focusing on objects to the detriment of their social world or in an attempt to avoid that social world. In either case, if these children are not experiencing successful peer interactions, they may be missing out on experiences that could positively impact their self-perceptions. In sum, while solitarypassive withdrawal at age 4 may have positive effects on the development of cognitive self-perceptions, results of this study support the evidence that there do appear to be problems in the social world of boys who engage in this nonsocial behavior.

By age 7, there are far fewer, if any, positive outcomes associated with the display of solitary-passive behavior by boys. Results revealed that this behavior predicted negatively to perceived peer acceptance, and perceived physical competence. It should be noted that the frequency of this behavior dropped significantly from age 4 to 7 years. Thus, as solitary-passive withdrawal becomes an increasingly infrequent behavior, but much more salient to peers, boys who engage in this behavior at age 7 may stand out as 'different', or at least perceive themselves of being different, resulting in less positive peer interactions and, subsequently, less positive self-perceptions. This is consistent with literature extant that indicates that solitary-passive withdrawal at age 7 becomes increasingly related to adjustment difficulties, including negative self-perceptions (Asendorpf, 1993).

\subsection{Reticence}

Unlike solitary-passive withdrawal, there have been few, if any, positive outcomes associated with reticent behavior in early childhood. For both boys and girls, reticence has been found to be associated with indices of anxiety, social maladjustment, peer rejection and negative emotionality (Coplan et al., 1994; Coplan \& Rubin, 1998; Hart et al., 2000; Rubin, 1982; Rubin, Coplan, et al., 1995). The results of the current study add to the growing list of adjustment problems associated with reticent behavior, especially for boys. Specifically, findings revealed that reticence in boys was negatively associated with observed peer acceptance (at ages 4 and 7 years), perceived peer acceptance, perceived physical competence, and perceived cognitive competence. These are particularly disturbing findings given that early childhood is typically a time period during which children tend to have extremely positive, even overinflated, selfperceptions (Harter, 1998, 1999; Harter \& Pike, 1984). Thus, even in early childhood, reticent boys appear to be having both negative experiences (i.e., few successful peer encounters) and self-doubt which may begin to feed off each other in a downward spiral of negativity. 


\subsection{Peer acceptance}

As hypothesized, the results of this study suggest that peer acceptance plays a role in the development of self-perceptions, especially for girls. Specifically, observed peer acceptance at age 4 was a positive, albeit modest, predictor of both cognitive and physical self-perceptions for girls. This supports the notion that, even early in life, relationships with others are important to girls (Chodorow, 1989; Gilligan, 1982; Huston, 1983; Miller, 1986). Given the importance of peer acceptance for girls, the findings of this study raise some concern regarding nonsocial behaviors for girls. Specifically, both reticence and solitary-passive withdrawal were negatively related to observed peer acceptance at both ages 4 and 7 . It is possible that being sociable may put girls in a position to receive the type of positive feedback (i.e., acceptance by peers) that helps them to feel good about themselves and their abilities. Conversely, that may also mean that nonsocial girls may miss out on the type of positive interactions that promote positive self-perceptions of competence. For example, solitary-passive withdrawal at age 4 was negatively correlated with peer acceptance for both boys and girls but (a) solitary-passive behavior at 4 predicted positive cognitive selfperceptions for boys but not girls and (b) peer acceptance at age 4 predicted to negative self-perceptions in girls but not boys. Hence, this apparent divergence in patterns for boys and girls may be accounted for by the important role that relationships play for girls. Future work should more closely examine the role that peer acceptance may play as a mediator between nonsocial behaviors and indicators of adjustment or maladjustment for girls.

\subsection{Implications for practice}

The findings from this study have several significant implications for practice. Most importantly, results provide further evidence that social withdrawal in early childhood is a risk factor for maladjustment and, therefore, should give cause for concern to educators. It is often the case that teachers' time is devoted to those children who are being disruptive and causing physical harm to others. Because withdrawn children seldom distract from the learning atmosphere of the classroom or pose a significant risk to others, they simply do not demand the attention of their teachers. However, just because these children do not literally scream out for attention does not mean they do not need their teachers' help.

\subsection{Limitations and future directions}

There are several issues that should be taken into account when interpreting the findings from the present study and conducting future work in this area. In the present study, observations were conducted in a laboratory setting among unfamiliar peers. Observational methodologies conducted in a laboratory setting address several important issues (e.g., assess actual child behavior rather than employing outside informants such as parents or teachers) but also raise several questions. First, the concern always exists regarding the generalizability of results found in an artificial setting among unfamiliar peers to actual peer settings (e.g., playground, classroom) among familiar peers. The "unnatural" setting might account for the lack of findings regarding peer acceptance and perceived peer acceptance in the present study. For example, being accepted or rejected by unfamiliar peers may have very little bearing on how a child feels in regard to relationships with his or her actual peer group. However, a basic assumption in laboratory research is that the behaviors displayed are reflective of behavior in natural settings and, therefore, tell researchers something about children's actual patterns of interacting with their peers. Nonetheless, future 
research should observe social initiations in natural settings (i.e., classroom, playground) in an effort to further examine the impact of direct acceptance and rejection (as opposed to rating scales and nominations) on the developing self.

Furthermore, other indices of acceptance/rejection should be employed because the success or failure of social initiations is just one form of feedback for children and is extremely dependent on the other children who are present. For example, one must consider the number of successful initiations a child would experience if placed in a room with three reticent children versus being placed in a room with three aggressive children or with three sociable children. Classrooms and playgrounds provide children a larger range of children with whom they can choose to interact. Therefore, future work should be conducted in these and other natural settings in order to capture a potentially more accurate reflection of success and failure in social initiations. Future work should also examine rejection along with acceptance. For example, it may be more telling to examine the proportion of successful initiations to total initiations because positive feedback may be negated by similar amounts of rejection (i.e., failed initiation attempts).

Next, future work should examine the emotional and cognitive processes that may accompany acceptance or rejection. For example, if a child's initiation attempt is rejected, the display of negative affect may be an indication that the child is affected by his or her failure. If that is the case, one would expect that child to develop more negative self-perceptions than the child who is not affected emotionally by rejection. It would be important for future work to examine the role that emotions and self-critical thoughts have on the internalizing of acceptance and rejection by peers.

Finally, future work should attempt to examine other aspects of nonsocial children's lives that might influence developing self-perceptions including the influence of parents, temperament, and other physiological factors. Furthermore, longitudinal work should be conducted to examine the outcomes for nonsociable children with low self-perceptions at age 7 as they enter the middle childhood years.

\section{Conclusions}

Despite this study's limitations, its results make significant contributions to the literature extant regarding the development of self-perceptions in early childhood. In particular, it advances current knowledge in the following ways. First, it is one of the first studies to longitudinally examine, across the early-childhood years, the complex relations between nonsocial behaviors, peer interactions, and self-perceptions in a variety of domains. Second, it is the first study to examine the relations between specific types of nonsocial behaviors (i.e., reticence and solitary-passive withdrawal), as opposed to global ratings of withdrawal, and the development of self-perceptions in early childhood. Third, it is one of the first studies to examine the aforementioned relations using observed indices of peer acceptance rather than sociometric rating scores of acceptance. Fourth, the results demonstrate that specific nonsocial behaviors and observed peer acceptance begin to predict self-perceptions as early as age 4 years. Finally, findings from this study show that gender plays a role in how these behaviors and interactions influence self-perceptions. Specifically, positive interactions with peers as early as age 4 years influence the development of positive self-perceptions of competence in girls. On the other hand, nonsocial behaviors appear to have a direct impact on the development of self-perceptions in boys. Specifically, the impact that reticent behavior has on boys' self-perceptions is, without exception, negative. For solitary-passive withdrawal, there are some positive outcomes associated with its display by boys at age 4, but by age 7 it too is detrimental to emerging self-perceptions. In sum, early childhood is not too early to begin examining the development 
of self-perceptions because there are important aspects of the social lives of both boys and girls that are predictive of emerging beliefs about the self.

\section{References}

Asendorpf, J. B. (1990). Beyond social withdrawal: Shyness, unsociability and peer avoidance. Human Development, 33, 250-259.

Asendorpf, J. B. (1991). Development of inhibited children's coping with unfamiliarity. Child Development, 62, $1460-1474$.

Asendorpf, J. B. (1993). Beyond temperament: A two-factor coping model of the development of inhibition during childhood. In K. H. Rubin \& J. Asendorpf (Eds.), Social withdrawal, inhibition, and shyness in childhood (pp. 265-290). Hillsdale, NJ: Erlbaum.

Berndt, T. J., \& Burgy, L. (1996). The social self-concept. In B. A. Bracken (Ed.), Handbook of self-concept (pp. 171-209). New York: Wiley.

Boivin, M., \& Begin, G. (1989). Peer status and self-perceptions among early elementary school children: The case of rejected children. Child Development, 60, 591-596.

Boivin, M., \& Hymel, S. (1997). Peer experiences and social self-perceptions: A sequential model. Developmental Psychology, $33,135-145$.

Caspi, A., Elder, G. H., \& Bem, D. J. (1988). Moving away from the world: Life-course patterns of shy children. Developmental Psychology, 24, 824-831.

Chodorow, N. (1989). Feminism and psychoanalytic theory. New Haven, CT: Yale University Press.

Cooley, C. H. (1902). Human nature and the social order. NY: Charles Schribner's Sons.

Coplan, R. J., Molina, M. G., Lagace-Seguin, D. G., \& Wichmann, C. (2001). When girls versus boys play alone: Gender differences in the relations between nonsocial play and adjustment in Kindergarten. Developmental Psychology, 37, 464-474.

Coplan, R. J., \& Rubin, K. H. (1998). Exploring and assessing nonsocial play in the preschool: The development and validation of the preschool play behavior scale. Social Development, 7, 72-91.

Coplan, R. J., Rubin, K. H., Fox, N. A., Calkins, S. D., \& Stewart, S. L. (1994). Being alone, playing alone, and acting alone: Distinguishing among reticence and passive and active solitude in young children. Child Development, 65, 129-137.

Engfer, A. (1993). Antecedents and consequences of shyness in boys and girls: A 6-year longitudinal study. In K. H. Rubin \& Asendorpf (Eds.), Social withdrawal, inhibition, and shyness in childhood (pp. 49-79). Hillsdale, NJ: Erlbaum.

Gilligan, C. F. (1982). In a different voice. Cambridge, MA: Harvard University Press.

Hart, C. H., Yang, C., Nelson, L. J., Robinson, C. C., Olsen, J. A., Nelson, D. A., et al. (2000). Peer acceptance in early childhood and subtypes of socially withdrawn behavior in China, Russia, and the United States. International Journal of Behavioral Development, 24, 73-81.

Harter, S. (1998). The development of self-representations. In: W. Damon (Series Ed.) \& N. Eisenberg (Vol. Ed.), Handbook of child psychology: Vol. 3, Social, emotional, personality development (5th ed., pp. 553-617). New York: Wiley.

Harter, S. (1999). The construction of the self. New York: Guilford Press.

Harter, S., \& Jackson, B. K. (1993). Young adolescents' perceptions of the link between low self-worth and depressed affect. Journal of Early Adolescence, 33, 383-407.

Harter, S., Marold, D. B., \& Whitesell, N. R. (1992). A model of psychological risk factors leading to suicidal ideation in young adolescents. Development and Psychopathology, 4, 167-188.

Harter, S., \& Pike, R. (1984). The pictorial scale of perceived competence and social acceptance for young children. Child Development, 55, 1969-1982.

Heatherton, T. F., \& Baumeister, R. F. (1991). Binge eating as escape from self-awareness. Psychological Bulletin, 100, 86-108.

Huston, A. C. (1983). Sex-typing. In P. Mussen \& E. M. Hetherington (Eds.), Handbook of child psychology: Vol.4, Socialization, personality, and social development (4th ed., pp. 387-467). New York: Wiley.

Hymel, S., Bowker, A., \& Woody, E. (1993). Aggressive versus withdrawn unpopular children: Variations in peer and self perceptions in multiple domains. Child Development, 64, 879-896.

Hymel, S., Rubin, K. H., Rowden, L., \& LeMare, L. (1990). Children's peer relationships longitudinal prediction of internalizing and externalizing problems from middle to late childhood. Child Development, 61, 2004-2021. 
Hymel, S., Woody, E., \& Bowker, A. (1993). Social withdrawal in childhood: Considering the child's perspective. In K. H. Rubin \& J. Asendorpf (Eds.), Social withdrawal, inhibition, and shyness in childhood (pp. 237-264). Hillsdale, NJ: Erlbaum.

Ladd, G. W., \& Price, J. M. (1986). Promoting children's cognitive and social competence: The relations between parent's perceptions of task difficulty and children's perceived and actual competence. Child Development, 57, 446-460.

Marsh, H. W. (1990). Causal ordering of academic self-concept and academic achievement: A multiwave, longitudinal panel analysis.

Mead, G. H. (1925). The genesis of the self and social control. International Journal of Ethics, 35, 251-273.

Mead, G. H. (1934). Mind, self, and society. Chicago: University of Chicago Press.

Miller, J. B. (1986). Toward a new psychology of women (2nd ed.). Boston: Beacon Press.

Morison, P., \& Masten, A. S. (1991). Peer reputation in middle childhood as a predictor of adaptation in adolescence: A seven year follow-up. Child Development, 62, 991-1007.

Radke-Yarrow, M., Richters, J., \& Wilson, W. E. (1988). Child development in a network of relationships. In R. A. Hinde \& J. Stevenson-Hinde (Eds.), Relationships with families: Mutual influences (pp. 48-67). Oxford: Clarendon Press.

Rubin, K. H. (1982). Nonsocial play in preschoolers: Necessarily evil? Child Development, 53, 651-657.

Rubin, K. H. (1985). Socially withdrawn children: An "at risk" population? In B. H. Schneider \& K. H. J. E. Ledingham (Eds.), Peer relationships and social skills in childhood: Issues in assessment and training (pp. 125-139). New York: Springer-Verlag.

Rubin, K. H. (1993a). The Play Observation Scale (POS). University of Waterloo.

Rubin, K. H. (1993b). The Waterloo longitudinal project: Correlates and consequences of social withdrawal from childhood to adolescence. In K. H. Rubin \& J. Asendorpf (Eds.), Social withdrawal, inhibition and shyness in children (pp. 291-314). Hillsdale, NJ: Erlbaum.

Rubin, K. H., Burgess, K. B., Kennedy, A. E., \& Stewart, S. L. (2003). Social withdrawal in childhood. In E. J. Mash \& R. A. Barkley (Eds.), Child Psychopathology (2nd ed.). New York, NY: Guilford, pp. 372-406.

Rubin, K. H., Chen, X., \& Hymel, S. (1993). Socioemotional characteristics of withdrawn and aggressive children. Merrill-Palmer Quarterly, 39, 518-534.

Rubin, K. H., Chen, X., McDougall, P., Bowker, A., \& McKinnon, J. (1995). The Waterloo longitudinal Project: Predicting internalizing and externalizing problems in adolescence. Developmental and Psychopathology, 7, 751-764.

Rubin, K. H., Coplan, R. J., Fox, N. A., \& Calkins, S. D. (1995). Emotionality, emotion regulation, and preschoolers' social adaptation. Development and Psychopathology, 7, 49-62.

Rubin, K. H., \& Mills, R. S. L. (1988). The many faces of social isolation in childhood. Journal of Consulting and Clinical Psychology, 56, 916-924.

Simpson, A. E., \& Stevenson-Hinde, J. (1985). Temperamental characteristics of three-to-four-year-old boys and girls and child-family interactions. Journal of Child Psychology and Psychiatry, and Allied Disciplines, 26, 43-53.

Stevenson-Hinde, J. (1989). Behavioral inhibition: Issues of context. In J. S. Reznick (Ed.), Perspectives on behavioral inhibition (pp. 125-138). Chicago: University of Chicago Press.

Stewart, S. L., \& Rubin, K. H. (1995). The social problem-solving skills of anxious-withdrawn children. Development and Psychopathology, 7, 323-336.

Stoneman, Z., Brody, G. H., \& McKinnon, C. E. (1984). Naturalistic observations of children's activities and roles when playing with their siblings and friends. Child Development, 55, 617-627.

Younger, A., Gentile, C., \& Burgess, K. (1993). Children's perceptions of social withdrawal: Changes across age. In K. H. Rubin \& J. Asendorpf (Eds.), Social withdrawal, inhibition, and shyness in childhood (pp. 215-235). Hillsdale, NJ: Lawrence Erlbaum Associates. 